\section{$\underset{\substack{\text { hommes } \\ \text { \& migrations }}}{ }$}

\section{Hommes \& migrations}

Revue française de référence sur les dynamiques

migratoires

$1326 \mid 2019$

Londres et ses migrations

\title{
Fawaz Hussain, Le Syrien du septième étage,
}

Paris, Le Serpent à Plumes, 2018, 240 pages, $18 €$

\section{Mustapha Harzoune}

\section{OpenEdition}

1 Journals

\section{Édition électronique}

URL : https://journals.openedition.org/hommesmigrations/9913

DOI : 10.4000/hommesmigrations.9913

ISSN : 2262-3353

Éditeur

Musée national de l'histoire de l'immigration

Édition imprimée

Date de publication : 1 juillet 2019

Pagination : 185

ISBN : 978-2-919040-46-9

ISSN : $1142-852 X$

Référence électronique

Mustapha Harzoune, «Fawaz Hussain, Le Syrien du septième étage, », Hommes \& migrations [En ligne], 1326 | 2019, mis en ligne le 01 juillet 2019, consulté le 16 janvier 2022. URL : http://

journals.openedition.org/hommesmigrations/9913; DOI : https://doi.org/10.4000/

hommesmigrations.9913 


\section{Livres}

\section{Le Syrien du septième étage}

Fawaz Hussain, Paris, Le Serpent à Plumes, 2018, 240 pages, $18 €$.

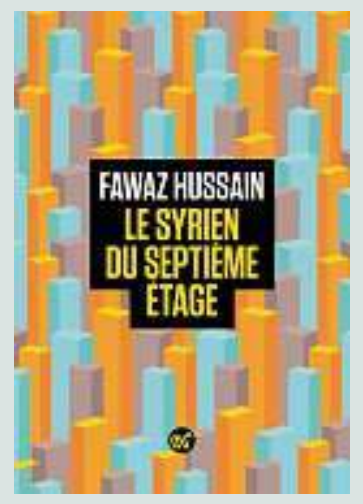

Il est impossible de lire le mot «Syrien» sans être renvoyé à la tragédie orchestrée par «le boucher de Damas». D'ailleurs, à l'heure de l'info distillée en un goutte-àgoutte «obsessionnel», que notre Syrien polyglotte s'inflige en français, en anglais et en arabe, le risque d'un coup de sang guette: "je m'enlise dans les sables mouvants, trébuche dans mes entrailles, je n'en peux plus». Se refaire une santé n'est pas à la portée du premier exilé venu. Mais se refaire la pilule quand, de votre terre, remontent des odeurs de sang et des images de mort, cela devient mission impossible. Car ce Syrien, bon an mal an, avait fait son trou dans le pays de Voltaire. "Intégré», «naturalisé », il a travaillé et servi le bien commun. Mais pas de lauriers pour ce bon élève de la République. Juste une rachitique retraite qui l'oblige à engraisser ses artères de poulets à 6,50 euros, essuyant au passage les railleries de son soiffard de boucher. Certains soirs, il noie sa tristesse dans une bouteille de vin, «confidente» et "ennemie intime».
À cette «nostalgie tenace» qui revient en un entêté boomerang télévisuel, aux désillusions de l'exil, voici que s'en dessine un autre: "Avancer en âge, c'est s'engager dans un tunnel dont la mort est l'unique issue. Décidément, de cette chienne de vie on ne sortira jamais vivant. » Et oui, la pente de la rue du Surmelin «devient de plus en plus raide» quand la libido de pépère baisse petit à petit. Et pourtant, le cœur reste vert, titillé par «la beauté des Maliennes aux hanches aussi vastes que le Sahara» et par la Russe longiligne du rez-dechaussée, qui, poutinesque à souhait, snobe, daube et zappe les avances du Levantin. Il lui reste à se réfugier dans les rêves - "le rêve est la vraie réalité épurée de tout ce qui l'altère» - ou dans le souvenir de sa compagne nipponne qu'il a, le con! (tant il regrette sa décision), laisser partir un jour de néfaste lucidité.

Il est seul, avec ses souvenirs, les images de son pays et les coups de fil de sa mère, isolée au milieu du «chaos orchestré par toutes les forces du mal régionales et mondiales et la phraséologie nasillarde des islamistes», seule dans «la tombe de l'Humanité». Entre deux reportages qui le «condamnent» à ses «racines de poussière et de sang», notre Syrien raconte son HLM coincé entre les Maréchaux et le périphérique du côté de la Porte de Bagnolet. S'esquisse alors un tableau impressionniste des immigrations, un maelström en chair et en os de visages, de langues, de situations, d'odeurs, de comportements... la vie sous sa fenêtre, loin des stats et des doxas. Ce HLM, c'est la Tour de Babel des exilés et des malheurs du monde: le voisin serbe y croise la jeune tamoule, un vigile kabyle par trop colérique côtoie une compatriote qui pleure Aït Ahmed; le discret chinois tranche avec le chibani revenu du bled lesté d'une belle «Amazighe de Ouarzazate»; les éboueurs maliens du rez-dechaussée sont plus «discrets» que «leur cuisine» et les gardiens débarquent du Portugal. Au quatrième, reste un couple de retraité français, des «rescapés», oubliés de Dieu et de leur rejeton. Et lorsque l'extérieur s'invite, c'est à coups de pizzas préparées par des Égyptiens, livrées «par de petits Mamadou et Ibrahima», ou que les travaux d'entretien sont soustraités à l'envi jusqu'à faire intervenir des étrangers venus des quatre coins du monde. Le centre prospère et la marge turbine.

Le "naufrage de l'humanité» s'étale aussi dans ce "capitalisme pernicieux» qui multiplie les «laissés-pour-compte». Dans cette «cité mouroir» où les chants kabyles et les mélodies arabes sont remplacés par les versets du coran, où «des baskets fatiguées et des casseroles déformées» ont chassé les pots de fleurs. La France serait «bonne pour la casse» dit le vigile kabyle. "Échoué en périphérie de Paris, cet autre paquebot recèle autant de petites vies cabossées, broyées par une société de plus en plus déshumanisée et me renvoie mon propre naufrage.»

L'écriture de Fawaz Hussain est ici plus dense et plus poétique. Il semble avoir soumis cette langue française (qu'il chérit) à sa propre voix, à sa propre musique. Le ton est railleur et tranché. Tout pourrait être triste, n'était justement ce ton, cette distance, ce mordant, dans ce récit où ce qui se joue n'est rien d'autre que la vie ou la mort. Mustapha Harzoune 